\title{
Enhancement in Biodiesel Blend with the Aid of Neural Network and SAPSO
}

\author{
Vinolin V \\ Department of Applied Electronics, \\ St.Xavier's Catholic College of Engineering \\ Kanyakumari, Tamil Nadu, India \\ v.vinolin@gmail.com
}

\author{
Vinusha S \\ Department of Applied Electronics, \\ Regional Centre of Anna University \\ Tirunelveli, Tamil Nadu, India \\ s.vinu89@gmail.com
}

\begin{abstract}
Biodiesel is accessible in a number of diverse blends. It can be blended with petro-diesel or can be utilized as a fuel on its own. Hence, biogas run Dual Fuel Diesel Engines (DFDE) offer an attractive replacement for traditional diesel engines. Nevertheless, the biogas run DFDE are overwhelmed by the troubles of high emissions and low efficiency. Hence, this paper focuses on the issues related to conventional fuel diesels and has established a diesel oil blend with better efficiency. Moreover, a Self Adaptive Particle Swarm Optimization (SAPSO) is adopted to analyze the performance of engines and emissions. In addition, the proposed method is compared with Genetic Algorithm (GA) and PSO and the results are obtained.
\end{abstract}

Keywords: Biodiesel; Fuels; Neural network (NN); Self Adaptive Particle Swarm Optimization; Emission.

\section{Introduction}

The wide spread depletion of fossil fuels in recent times and their non-renewability, increasing cost and environmental concerns has led researchers in search of alternative energy resources [1]. Moreover, global carbon dioxide $\left(\mathrm{CO}_{2}\right)$ emissions from fossil-fuel combustion are increasing every year, intensifying air pollution and magnifying the global warming problems caused by $\mathrm{CO}_{2}$ [2]. Significant population growth and changes in lifestyle are resulting in ever increasing consumption of energy. Internal combustion engines play a pivotal role in the world's transportation, agriculture and many other sectors right from the industrial age [3]. Diesel fuel has versatile applications because of its high fuel efficiency compared to gasoline. Fossil fuels have a pivotal role in the world energy market [4].

Environmental concerns and limited amount of petroleum fuels have elicited the research of alternative renewable fuels for Internal Combustion (IC) engines [5]. Biogas, one such renewable fuel, can be used in the IC engine by modifying the engine suitably. In addition, anaerobic digestion of biomass results in the production of biogas [6] [7].

The main combustible constituent of biogas is methane, which can run in both compressions ignition (CI) and spark ignition (SI) engines [8]. The most conspicuous feature that supports the use of biogas in CI engines is that there is no debating of power detected in case of SI engines [9]. This is due to the extreme sensitivity of SI engines towards biogas composition leading to high cycle to cycle variations [10]. Biogas can be used in CI engines under dual fuel mode (DFM). The higher auto ignition temperature along with low energy density and low cetane number of biogas restricts its direct application in CI engine [11]. In DFM, a small amount of liquid fuel is supplied along with the gaseous fuel to initiate the combustion process. The liquid fuel is called the pilot fuel, which acts as a source of ignition for the gaseous fuel. The gaseous fuel is called the primary fuel on which the engine mainly runs [12].

The power output of the engine under DFM normally controlled by varying the flow of quantity of biogas. It is possible to achieve a substitution of diesel up to $85 \%$ by using biogas. Thus, biogas run dual fuel diesel engines present an environmentally attractive replacement for conventional diesel engines. However, the biogas run dual fuel diesel engines are plagued by the problems of low efficiency and high emissions [13]. This is because the operating parameters of a diesel engine are optimized for diesel fuel based on its chemical and physical properties. Therefore, for attainment of higher efficiency for running 
biogas under DFM, the operating parameters of the biogas run dual fuel diesel engine [14]. For meeting the stringent imposed emissions regulations, researchers have focused their interest either on the domain of engine- [15] or fuel-related techniques, such as alternative gaseous fuels of renewable nature or oxygenated fuels that can mitigate particulate emissions.

This paper contributes the crisis concerning the exploitation of traditional fuel- diesel and a diesel oil blend is introduced with different compression ratios of 15 and 17 and blend ratios of $6 \%$ and $7 \%$. Moreover, a novel modelling system known as SAPSO is adopted and the engine performance and emission analysis are performed. The implemented scheme is compared with conventional systems such as GA, PSO and SAPSO schemes and the results are verified. The paper is organized as follows. Section II explains the related works and reviews done under this topic. Moreover, section III analyses the modelling of biodiesel blending and section IV portrays the results and discussions. Finally, section V concludes the paper.

\section{Literature Review}

\subsection{Related Works}

In 2016, B.J. Bora and U.K. Saha [1] has suggested a technique to eradicate the negative collision of the dual fuel combustion on the environment and engine effectiveness by the pilot fuel Injection Timing (IT) optimization and Compression Ratio (CR) of a DFDE. For carrying out tests, a direct injection, $3.5 \mathrm{~kW}$ single cylinder, water cooled, variable CR Diesel Engine (DE) was transformed into a biogas run DFDE by linking a venture gas mixer. A group of arrangements including CRs of 18, 17.5, 17 and 16 at different loading conditions and ITs of $26^{\circ}, 29^{\circ}$ and $32^{\circ}$ Before Top Dead Centres (BTDCs) were measured for this analysis. Pilot fuel CR of 18 and IT of $29^{\circ}$ BTDC were established to be most favourable for this specific DE generating a highest brake thermal effectiveness of $25.44 \%$ together with a liquid fuel substitution of 82.11\%. In addition, the emissions of Hydro Carbon (HC) and Carbon Monoxide (CO) were discovered to be slightest for this specific setting.

In 2014, V. Gnanamoorthi and G. Devaradjane [2] has introduced a scheme to analyze the manipulation of CR on the combustion, performance and emission qualities of a logically aspirated DE. CR's namely, 17.5:1, 19.5:1 and 18.5:1 were measured and altered by varying the proportions of piston bowl by maintaining the volume of standard stroke. Investigations were carried out with five diverse blends of ethanol. Moreover, there is a noteworthy reduction in HC, smoke emissions and CO; anyhow there is a raise in Nitrogen Oxides (NOx) level.

In 2013, Rakopoulos et al. [3] has implemented a scheme, which estimates the exhaust emission and combustion features of cottonseed oil and its bio-diesel. Using this scheme, combustion chamber and fuel injection pressure characteristics were attained, and heat release rate scrutiny was carried out by exposing several motivating characteristics of the combustion systems. The experiments were performed by means of all the neat cottonseed oil or fuel blends or its neat bio-diesel functioning at three various loads. Moreover, the utilization of fuel, exhaust smoke, NOx, CO and total unburned HCs were evaluated.

In 2017, Senthur et al. [4] has introduced a scheme with Butylated Hydroxy Toluene (BHT) and nbutanol additive, which was exploited in a DE. Moreover, the consequences of BHT on engine computation and exhaust emissions were analyzed using this technique. The biodiesel generated from Methanol, waste cooking oil by transesterification process, sodium hydroxide $(\mathrm{NaOH})$, catalyst and sulphuric acid (H2SO4) were deployed in the reaction. Engine computation analyses were performed with blends and the outcomes have demonstrated that, B30 is the advanced blend between various other biodiesel blends.

In 2017, Natarajan et al. [5], has proposed a method that deals with the investigational study of the early direct injected HCCI. The performance scrutiny of the engine was performed by means of CHEMKIN-PRO Software. In addition, the performance examination was carried out by means of the auto ignition chemistry using minimized chemical kinetics. The bio ethanol - diesel blend (E20) and neat diesel fuels were utilized as fuel for these researches, and the combustion, emission and pressure features were analyzed in the correspondence ratio of 0.6.

\subsection{Review}

Table 1 shows the methods, features and challenges of conventional techniques based on bio-diesel blending methods. At first, Perturbation technique was suggested in [1] that generates a maximum brake thermal effectiveness with least emissions of $\mathrm{CO}$ and HC. However, NOX emission increases for 
high CR. In addition, Dual fuel direct injection was introduced in [2], which provides highest brake thermal efficiency and better minimization of smoke at higher loads, but the smoke increases with increase in CR. Moreover, was presented in [3] that do not necessitate solubilises and it further minimizes the stability issues of engine operation. Anyhow, there will be emission of $\mathrm{HC}$ at certain level. Similarly, transesterification was implemented in [4], which provides increased accuracy with reduced percentage of uncertainty, but issues may arise in entire fuel atomization. Finally, early direct injection was proposed in [5], which offers minimized emission of $\mathrm{HC}$ and it also more time for injection, however, pressure may get raised due to changes in temperature. These above mentioned challenges should be taken into consideration for motivating the developments in the bio-diesel fuel blending engines.

Table 1. Review on conventional bio-diesel fuel blending engines

\begin{tabular}{|c|c|c|c|}
\hline $\begin{array}{l}\text { Author } \\
\text { [citation] }\end{array}$ & $\begin{array}{l}\text { Adopted } \\
\text { methodology }\end{array}$ & Features & Challenges \\
\hline Bora et al. [1] & Perturbation technique & $\begin{array}{l}\text { * Generates a maximum brake } \\
\text { thermal effectiveness } \\
\text { * Least emissions of } \mathrm{CO} \text { and } \mathrm{HC} \text {. }\end{array}$ & $\begin{array}{l}\text { * NOx emission increases for high } \\
\text { CR. }\end{array}$ \\
\hline $\begin{array}{l}\text { Gnanamoorthi et } \\
\text { al. [2] }\end{array}$ & Dual fuel direct injection & $\begin{array}{l}\text { Highest brake thermal efficiency } \\
\text { * Better reduction of smoke at } \\
\text { higher loads }\end{array}$ & $\begin{array}{l}\text { * Smoke increases with increase in } \\
\text { CR }\end{array}$ \\
\hline $\begin{array}{l}\text { Rakopoulos et al. } \\
\text { [3] }\end{array}$ & MPSO algorithm & $\begin{array}{l}\text { * Do not require solubilises } \\
\text { - Minimizes stability issues of } \\
\text { engine operation }\end{array}$ & * Increased emission of $\mathrm{HC}$ \\
\hline Senthur et al. [4] & Transesterification & $\begin{array}{l}\text { * Increased accuracy } \\
\text { * Reduced percentage of } \\
\text { uncertainty }\end{array}$ & $\begin{array}{l}\text { * Problems may arise in entire fuel } \\
\text { atomization }\end{array}$ \\
\hline Natarajan et al. [5] & early direct injection & $\begin{array}{l}\text { Reduced emission of } \mathrm{HC} \\
\text { Advanced time for injection }\end{array}$ & $\begin{array}{l}\text { * Pressure may get raise due to } \\
\text { changes in temperature }\end{array}$ \\
\hline
\end{tabular}

\section{Modelling of Bio-Diesel Blending}

\subsection{System Design}

The blended fuel-TO-diesel oil is distributed to the Kirloskar SV1 designed diesel engine including directly injected, water cooled, four stroke one cylinder. The engine operates at a velocity of $1500 \mathrm{rpm}$ and produces a power of $5.2 \mathrm{~kW}$. The designing of the system furthermore involves the combustion analysis systems and the emission gas analyzer for scrutinizing the emission of $\mathrm{CO}, \mathrm{CO}_{2}, \mathrm{O}_{2}, \mathrm{NO}_{\mathrm{x}}, \mathrm{HC}$ gases and for investigating the specific air density, cylinder pressure, gas constant, polytrophic index, adiabatic index, correspondingly. The scrutinized data are examined and stored in $\mathrm{O} / \mathrm{P}$ reading. The data is gathered and it is assigned for the model learning technique by means of the $\mathrm{NN}$, which envisages the emission performance and the combustion features of engine performance.

Autoregressive Neural model: The Non-Linear Autoregressive exogenous input (NLARX) [17] design is one of the generally adopted structural design and its construction is specified in Fig.1.

Assume $\mathrm{X}(\mathrm{k})$ be the inputs and $\mathrm{Y}(\mathrm{k})$ be the outputs and the NLARX design is given by Eq. (1)

$$
\mathrm{Y}(\mathrm{l})=\mathrm{G}(\mathrm{Y}(\mathrm{l} \quad 1), \ldots, \mathrm{Y}(\mathrm{l} \quad \mathrm{P}), \mathrm{X}(\mathrm{l}), \ldots \mathrm{X}(\mathrm{l} \quad \mathrm{Q}=1))
$$

In which, $\mathrm{Q}$ and $\mathrm{P}$ indicates the count of earlier input parameters and output parameters correspondingly, which are exploited for assuming the present output. The produced outputs from the NLARX design are the transformation of the previous outputs and inputs that are really the regressor operations including two varieties of blocks, namely, nonlinear and linear blocks. The traditional regressors are owing to the belated output or input parameters however; the superior regressors subsist in the random user defined function structure of input variables and delayed output. As a result, the difficulty in NLARX design training can be a non linear unconstrained optimization problem and as given by Eq. (2).

$$
\min _{\omega}\left(\mu, \mathrm{V}_{\mathrm{T}}\right)=\frac{1}{2 \mathrm{~T}} \sum_{\mathrm{t}=1}^{\mathrm{T}}\left\|\mathrm{Y}_{\mathrm{t}}(1) \quad \hat{\mathrm{Y}}_{\mathrm{t}}(1 \mid \mu)\right\|^{2}
$$

In which, $\left.\mathrm{V}_{\mathrm{T}}=\left[\mathrm{Y}_{\mathrm{t}}(1), \mathrm{X}(1)\right] \mathrm{l}=1, \ldots ., \mathrm{T}, \quad \mathrm{Y}_{\mathrm{t}}(1), \quad \mathrm{Y}_{\mathrm{t}}(1), \quad \hat{\mathrm{Y}}_{\mathrm{t}}(1 \mid \mu), \mu\left(\mu=\mid \mu_{1}, \ldots, \mu_{\mathrm{i}}, \ldots, \mu_{\mathrm{p}}\right\rfloor\right),\|\|^{2}, \quad$ and $p$ denotes the training data set, the output which is measured in the training set, output of NLARX, vector factor, 2 
norm function and count of variables correspondingly. In the NN, specified in Eq. (1), an error variable said to be the performance index of the Eq. (2) is available and it is significant to reduce this index to prevail over the metric error. The index in addition demonstrates the approximation of network to specified training patterns and the network factors have to be customized to reduce the index over the whole trajectory for attaining the least value.

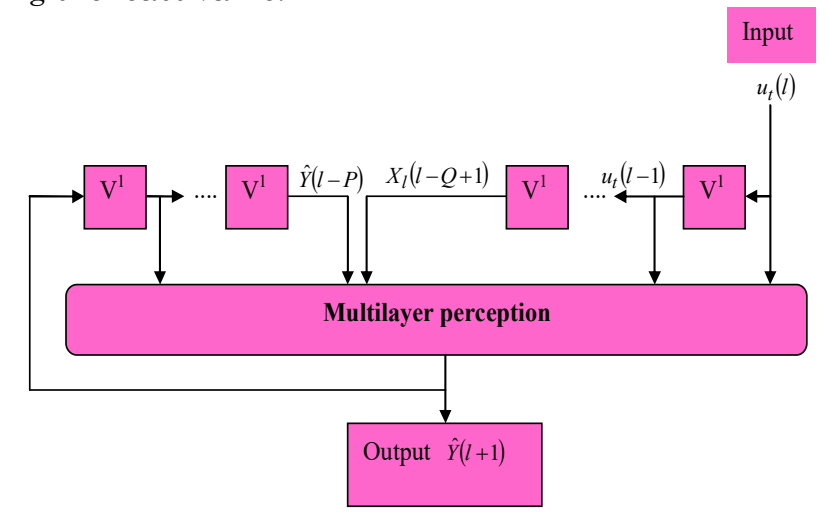

Fig. 1. Architecture of nonlinear autoregressive neural model.

\subsection{Conventional PSO}

The actual goal of the fundamental PSO technique is to reproduce the social communications between agents to resolve certain complicated optimisation issues [16]. Every agent in PSO is known as a particle and is related with a velocity that is adjusted based on its own flight experience. Hence, every particle is admired toward a stochastically weighted average of swarm's global best position and the personal best position. According to the fundamental PSO method, from iteration $k$ to $k+1$, every particle modifies its position and velocity as given by Eq. (3), in which $W$ is a real coefficient indicating the weight of inertia. $C_{1}$ and $C_{2}$ denotes the positive real coefficients indicating the cognitive and social acceleration factors, correspondingly.

$$
\begin{aligned}
& U_{m}^{k+1}=W U_{m}^{k}+C_{1} R_{1}\left(\text { pbes } m_{m}^{k} \quad X_{m}^{k}\right)+C_{2} R_{2}\left(\begin{array}{ll}
\text { gbes } k_{m}^{k} & X_{m}^{k}
\end{array}\right) \\
& X_{m}^{k+1}=X_{m}^{k}+U_{m}^{k+1}
\end{aligned}
$$

$R_{1}$ and $R_{2}$ are two arbitrary numbers equally distributed in $[0,1]$. pbest $_{m}^{k}$ indicates the personal best position of $m^{\text {th }}$ particle at iteration $k$. gbest indicates the swarm's global best position.

\subsection{Self Adaptive PSO}

When adopting PSO to resolve an optimisation crisis, it is necessary to control the exploitation and exploration potentials of particles appropriately to capably discover the global optimum. Preferably, the exploration ability desires to be assisted in the initial stage of the evolution, so that particles can wander through the entire solution space, instead of clustering about the best solution of the present population. Alternatively, the exploitation capacity is necessary to be supported in the delayed stage of the evolution, and hence the particles can concern on the local search to raise the prospect of discovering best possible solutions. The fundamental viewpoints regarding how the three control parameters manipulate the 2 capabilities of PSO is given subsequently. First is the large inertia weight that improves exploration, when a diminutive inertia weight assists exploitation. Second is a large cognitive constituent, distinguished with the social element, out coming in drifting of particles through the whole search space, which accordingly reinforces exploration. Third is a large social element, distinguished with the cognitive element that assists particles to a local search, thus intensifying the exploitation capacity. Although PSO intends at attaining a set of non-dominated solutions, how to attain a good equilibrium among the exploitation and exploration potentials of PSO remains a major problem in discovering enhanced nondominated solutions. Concentrating on improving the computation of PSO, this paper generates a novel PSO algorithm, known as SAPSO. The major intention of the improvement of SAPSO is to develop the performance of SAPSO by modifying its three control parameters to balance the exploitation and exploration potentials of particles. The suggested SAPSO is consequently incorporated into multiobjective optimisation (MOO) to discover non-dominated solutions with high-quality. For better -tuning of three control factors, a new self-adaptive approach is formulated as given by Eq. (4) to Eq. (9), in which 
$W_{\min }$ and $W_{\max }$ are the lower and upper bounds of the inertia weight, correspondingly. $C_{1 f}$ and $C_{1 s}$ denotes the final and initial values of the cognitive Acceleration Parameter (AP). $C_{2 f}$ and $C_{2 s}$ indicates the final and initial values of the social AP. Moreover, $k_{\max }$ refers to the highest iteration number. $\Delta$ signifies a adequately small positive real number. In addition, $\left\|U_{m}^{k+1}\right\|$ and $\left\|U_{m}^{k}\right\|$ indicates the

$L_{2}$-norm of the velocity vector of the $m^{t h}$ particle at iterations $k$ and $\left(\begin{array}{ll}k & 1\end{array}\right)$, correspondingly.

$$
\begin{aligned}
& \mathrm{W}_{\mathrm{m}}^{\mathrm{k}+1}=\left(\begin{array}{ll}
\mathrm{W}_{\max } & \mathrm{W}_{\min }
\end{array}\right) \exp \left(\frac{\delta_{\mathrm{W}} \mathrm{k}}{\beta_{\mathrm{m}}}\right)+\mathrm{W}_{\min } \\
& \mathrm{C}_{\mathrm{lm}}^{\mathrm{k}+1}=\left(\begin{array}{ll}
\mathrm{C}_{1 \mathrm{~s}} & \mathrm{C}_{1 \mathrm{f}}
\end{array}\right) \exp \left(\frac{\delta_{\mathrm{C} 1} \mathrm{k}}{\beta_{\mathrm{m}}}\right)+\mathrm{C}_{1 \mathrm{f}} \\
& \mathrm{C}_{2 \mathrm{~m}}^{\mathrm{k}+1}=\left(\begin{array}{ll}
\mathrm{C}_{2 \mathrm{~s}} & \left.\mathrm{C}_{2 \mathrm{f}}\right) \exp \left(\frac{\delta_{\mathrm{C} 2} \mathrm{k}}{\beta_{\mathrm{m}}}\right)+\mathrm{C}_{2 \mathrm{f}} \\
\delta_{\mathrm{C} 1}=\frac{\left(\mathrm{C}_{1 \mathrm{~s}}\right.}{\mathrm{C}_{1 \mathrm{f}}}
\end{array}\right) \\
& \left.\delta_{\mathrm{C} 2}=\frac{\left(\mathrm{C}_{2 \mathrm{~s}}\right.}{\mathrm{C}_{2 \mathrm{f}}}\right) \\
& \beta_{\mathrm{m}}=\frac{\left\|\mathrm{U}_{\mathrm{m}}^{\mathrm{k}+1}\right\|+\left\|\mathrm{U}_{\mathrm{m}}^{\mathrm{k}}\right\|}{2\left\|\mathrm{U}_{\mathrm{m}}^{\mathrm{k}+1}\right\|+\Delta}
\end{aligned}
$$

Observe that $C_{2 s}<C_{2 f}$ and $C_{1 s}>C_{1 f}$ in the proposed self-adaptive approach.

\section{Results and Discussions}

The proposed bio-diesel blending technique was simulated in MATLAB and the results were obtained. Moreover, the proposed scheme was compared with conventional algorithms such as GA [18] and PSO [19] and the results were obtained. In addition, statistical analysis for various emissions such as $\mathrm{CO}_{2}, \mathrm{HC}, \mathrm{CO}$ and $\mathrm{NO}_{\mathrm{x}}$ were analyzed for varying CR's.

\subsection{Statistical Interpolation}

The statistical analysis for the proposed SAPSO model for emissions such as $\mathrm{CO}_{2}, \mathrm{HC}, \mathrm{CO}$ and $\mathrm{NO}_{\mathrm{x}}$ are depicted by Table 2 to Table 5 respectively. From Table 2, $\mathrm{CO}_{2}$ emission can be obtained for CR of $15 \%$, where, the ratio of blend at $6 \%$ is $76.9 \%, 72.3 \%$ and $92.3 \%$ deviated by GA, PSO and SAPSO schemes respectively. Also, at ratio of blend of $7 \%$, is $66.12 \%, 45.16 \%$ and $35.4 \%$ deviated by GA, PSO and SAPSO schemes respectively. In addition, the blend ratio of $8 \%$ is $34.4 \%, 27.86 \%$ and $3.27 \%$ deviated by GA, PSO and SAPSO schemes correspondingly. Similarly, for CR of $17 \%$, the blend ratio at $6 \%$ is $5.45 \%, 3.63 \%$ and $9 \%$ deviated by GA, PSO and SAPSO schemes respectively. In addition, at ratio of blend of $7 \%$, is $3.44 \%$, $1.72 \% 12.06 \%$ deviated by GA, PSO and SAPSO schemes respectively. In addition, the blend ratio of $8 \%$ is $3.33 \%, 1.66 \%$ and $16.6 \%$ deviated by GA, PSO and SAPSO schemes respectively. Accordingly, HC emission can be attained from Table 3, where, the ratio of blend at $6 \%$ is $11.25 \%, 6.25 \%$ and $11.25 \%$ deviated by GA, PSO and SAPSO schemes respectively. Also, at ratio of blend of $7 \%$, is $19.35 \%, 5.16 \%$ and $3.12 \%$ deviated by GA, PSO and SAPSO schemes respectively. Similarly, for CR of $17 \%$, the blend ratio at $6 \%$ is $5.71 \%, 35.23 \%$ and $5.71 \%$ deviated by GA, PSO and SAPSO schemes respectively. In addition, at ratio of blend of $7 \%$, is $27.7 \%, 27.7 \%$ and $50 \%$ deviated by GA, PSO and SAPSO schemes respectively. Similarly, CO emission can be attained from Table 4 , where the ratio of blend at $6 \%$ for CR of $15 \%$ is $5.5 \%, 8.33 \%$ and $2.77 \%$ deviated by GA, PSO and SAPSO schemes respectively. Also, at ratio of blend of $7 \%$, is $8.57 \%, 2.85 \%$ and $8.57 \%$ deviated by GA, PSO and SAPSO schemes respectively. Similarly, for CR of $17 \%$, the blend ratio at $6 \%$ is $2.85 \%, 2.85 \%$ and $28.5 \%$ deviated by GA, PSO and SAPSO schemes respectively. In addition, at ratio of blend of $7 \%$, is $25 \%, 18.75 \%$ and $18.75 \%$ deviated by GA, PSO and SAPSO schemes respectively. Moreover, $\mathrm{NO}_{\mathrm{x}}$ emission is attained from Table 5, where the CR of $15 \%$ for blend ratio of $6 \%$ is $9 \%, 4.54 \%$ and $2.27 \%$ deviated by GA, PSO and SAPSO schemes respectively. Also, at ratio of blend of $7 \%$, is $5 \%, 12.5 \%$ and $7.5 \%$ deviated by GA, PSO and SAPSO schemes respectively. Similarly, for CR of $17 \%$, the blend ratio at $6 \%$ is $50 \%, 2.5 \%$ and $6.25 \%$ deviated by GA, PSO and SAPSO schemes respectively. In addition, at ratio of blend of $7 \%$, is $46.3 \%, 7.31 \%$ and 
Enhancement in Biodiesel Blend with the Aid of Neural Network and SAPSO

$53.65 \%$ deviated by GA, PSO and SAPSO schemes correspondingly. Thus the emissions for varying CR's with respect to the blend ratio were obtained from the analysis.

Table 2. Statistical interpolation of miniature blends for $\mathrm{CO}_{2}$ under varying compression ratio.

\begin{tabular}{llll}
\hline \multicolumn{5}{c}{ Compression ratio } & $\mathbf{1 5 \%}$ & \\
\hline & \multicolumn{2}{c}{ Blending ratio } \\
Methods & $6 \%$ & $7 \%$ & $8 \%$ \\
Actual & 0.65 & 0.62 & 0.61 \\
GA [18] & 0.15 & 0.21 & 0.4 \\
PSO [19] & 0.18 & 0.34 & 0.44 \\
SAPSO & 0.05 & 0.4 & 0.59 \\
Methods & Compression ratio & $17 \%$ & $8 \%$ \\
Actual & $6 \%$ & $7 \%$ & 0.6 \\
GA & 0.55 & 0.58 & 0.58 \\
PSO & 0.52 & 0.56 & 0.59 \\
SAPSO & 053 & 0.57 & 0.7 \\
\hline
\end{tabular}

Table 3. Statistical interpolation of miniature blends for HC under varying compression ratio.

\begin{tabular}{l|lll}
\hline & \multicolumn{4}{l}{ Compression ratio } & $\mathbf{1 5 \%}$ \\
\hline & \multicolumn{4}{c}{ Blending ratio } \\
Methods & $6 \%$ & $7 \%$ & $8 \%$ \\
\hline Actual & 16 & 15.5 & 13.9 \\
GA [18] & 14.2 & 12.5 & 10 \\
PSO [19] & 15 & 14.7 & 12.3 \\
SAPSO & 17.8 & 16 & 8 \\
& Compression ratio & $17 \%$ & $8 \%$ \\
Methods & $6 \%$ & $7 \%$ & 8.1 \\
Actual & 10.5 & 9 & 7.8 \\
GA [18] & 6 & 6.5 & 8 \\
PSO [19] & 5 & 6.5 & 11.5 \\
\hline SAPSO & 16.5 & 13.5 & \\
\hline
\end{tabular}

Table 4. Statistical interpolation of miniature blends for CO under varying compression ratio.

\begin{tabular}{|c|c|c|c|}
\hline \multicolumn{4}{|c|}{ Compression ratio $15 \%$} \\
\hline & \multicolumn{3}{|c|}{$\begin{array}{ll}\text { Blending ratio }\end{array}$} \\
\hline Methods & $6 \%$ & $7 \%$ & $8 \%$ \\
\hline Actual & 0.036 & 0.035 & 0.034 \\
\hline GA [18] & 0.034 & 0.038 & 0.035 \\
\hline PSO [19] & 0.033 & 0.034 & 0.036 \\
\hline SAPSO & 0.035 & 0.038 & 0.042 \\
\hline \multicolumn{4}{|c|}{ Compression ratio $17 \%$} \\
\hline Methods & $6 \%$ & $7 \%$ & $8 \%$ \\
\hline Actual & 0.035 & 0.032 & 0.03 \\
\hline GA [18] & 0.036 & 0.04 & 0.045 \\
\hline PSO [19] & 0.036 & 0.038 & 0.04 \\
\hline SAPSO & 0.025 & 0.026 & 0.028 \\
\hline
\end{tabular}

Table 5. Statistical interpolation of miniature blends for NOx under varying compression ratio.

\begin{tabular}{l|ccc}
\hline \multicolumn{5}{c}{ Compression ratio } & $\mathbf{1 5 \%}$ & \\
\hline & \multicolumn{4}{c}{ Blending ratio } \\
Methods & $6 \%$ & $7 \%$ & $8 \%$ \\
Actual & 44 & 40 & 35 \\
GA [18] & 40 & 42 & 45 \\
PSO [19] & 42 & 45 & 50 \\
SAPSO & 45 & 43 & 33 \\
& Compression ratio & $\mathbf{1 7} \%$ & $8 \%$ \\
Methods & $6 \%$ & $7 \%$ & 42 \\
Actual & 40 & 41 & 25 \\
GA [18] & 20 & 22 & 35 \\
PSO [19] & 39 & 38 & 58 \\
SAPSO & 65 & 63 & \\
\hline
\end{tabular}

\section{Conclusion}

This paper has presented the problems regarding the use of conventional fuel- diesel and introduced the diesel oil blend with different compression ratios of 15 , and 17 and blend ratios of $6 \%$ and $7 \%$. Moreover, a novel modelling technique called SAPSO is implemented and the engine performance and emission analysis were performed. From the simulation results, $\mathrm{CO}_{2}$ emission was obtained for $\mathrm{CR}$ of $15 \%$, where, the ratio of blend at $6 \%$ was $76.9 \%, 72.3 \%$ and $92.3 \%$ deviated by GA, PSO and SAPSO schemes 
respectively. Accordingly, $\mathrm{HC}$ emission was attained, where; the ratio of blend at $6 \%$ was $11.25 \%, 6.25 \%$ and $11.25 \%$ deviated by GA, PSO and SAPSO schemes respectively. Similarly, CO emission was attained from Table 4 , where the ratio of blend at $6 \%$ for CR of $15 \%$ was $5.5 \%, 8.33 \%$ and $2.77 \%$ deviated by GA, PSO and SAPSO schemes correspondingly. Furthermore, $\mathrm{NO}_{\mathrm{x}}$ emission was attained, where the CR of $15 \%$ for blend ratio of $6 \%$ was $9 \%, 4.54 \%$ and $2.27 \%$ deviated by GA, PSO and SAPSO schemes respectively. Thus the various emissions related to biodiesel blend were analyzed successfully.

\section{Compliance with Ethical Standards}

Conflicts of interest: Authors declared that they have no conflict of interest.

Human participants: The conducted research follows the ethical standards and the authors ensured that they have not conducted any studies with human participants or animals.

\section{References}

[1] B.J. Bora and U.K. Saha, "Optimisation of injection timing and compression ratio of a raw biogas powered dual fuel diesel engine," Applied thermal engineering, vol.92, pp. 111-121, January 2016.

[2] V. Gnanamoorthi and G. Devaradjane, "Effect of compression ratio on the performance, combustion and emission of DI diesel engine fueled with ethanol - Dieselblend," Journal of the energy institute, pp. 1-8, 2014.

[3] D.C. Rakopoulos, "Combustion and emissions of cottonseed oil and its bio-diesel in blends with either n-butanol or diethyl ether in HSDI diesel engine", Fuel, vol. 105, pp. 603-613, March 2013.

[4] S. Senthur Prabu, M.A. Asokan, Rahul Roy, Steff Francis, M.K. Sreelekh, "Performance, combustion and emission characteristics of diesel engine fuelled with waste cooking oil bio-diesel/diesel blends with additives", Energy, vol. 122, pp. 638-648, 1 March 2017.

[5] S. Natarajan, M. Akshay kumar, A.U. Meenakshi Sundareswaran, "Computational Analysis of an Early Direct Injected HCCI Engine Using Bio Ethanol and Diesel Blends as Fuel”, Energy Procedia, vol. 105, pp. 350-357, May 2017.

[6] 6. S. Natarajan, S. Abhinav Shankar, A.U. Meenakshi Sundareswaran, "Early Injected PCCI Engine Fuelled with Bio Ethanol and Diesel Blends - An Experimental Investigation", Energy Procedia, vol. 105, pp. 358-366, May 2017.

[7] Zhi Chao Ong, Mohd Bakar Mohd Mishani, Wen Tong Chong, Roon Sheng Soon, Zubaidah Ismail, "Identification of optimum Calophyllum inophyllum bio-fuel blend in diesel engine using advanced vibration analysis technique”, Renewable Energy, vol. 109, pp. 295-304, August 2017.

[8] Soha S.M. Mostafa, Nour Sh. El-Gendy, "Evaluation of fuel properties for microalgae Spirulina platensis biodiesel and its blends with Egyptian petro-diesel", Arabian Journal of Chemistry, vol. 10, Supplement 2, pp. s2040-s2050, May 2017.

[9] Manuel Garcia-Perez, Jun Shen, Xiao Shan Wang, Chun-Zhu Li, "Production and fuel properties of fast pyrolysis oil/bio-diesel blends", Fuel Processing Technology, vol. 91, no. 3, pp. 296-305, March 2010.

[10] R. El-Araby, Ashraf Amin, A.K. El Morsi, N.N. El-Ibiari, G.I. El-Diwani, "Study on the characteristics of palm oil-biodiesel-diesel fuel blend", Egyptian Journal of Petroleum, 21 March 2017.

[11] Shiliang Wu, Hongwei Yang, Jun Hu, Dekui Shen, Rui Xiao, "The miscibility of hydrogenated bio-oil with diesel and its applicability test in diesel engine: A surrogate (ethylene glycol) study", Fuel Processing Technology, vol. 161, pp. 162-168, 15 June 2017.

[12] Carlo Beatrice, Pierpaolo Napolitano, Chiara Guido, "Injection parameter optimization by DoE of a light-duty diesel engine fed by Bio-ethanol/RME/diesel blend”, Applied Energy, vol. 113, pp. 373-384, January 2014.

[13] Md Nurun Nabi, Ali Zare, Farhad M. Hossain, Timothy A. Bodisco, Richard J. Brown, "A parametric study on engine performance and emissions with neat diesel and diesel-butanol blends in the 13-Mode European Stationary Cycle”, Energy Conversion and Management, vol. 148, pp. 251-259, 15 September 2017.

[14] Arkadiusz Jamrozik, "The effect of the alcohol content in the fuel mixture on the performance and emissions of a direct injection diesel engine fueled with diesel-methanol and diesel-ethanol blends", Energy Conversion and Management, vol. 148, pp. 461-476, 15 September 2017.

[15] Arakshita Majhi, Y.K. Sharma, D.V. Naik, "Blending optimization of Hempel distilled bio-oil with commercial diesel”, Fuel, vol. 96, pp. 264-269, June 2012.

[16] Biwei Tang, Zhanxia Zhu, Hyo-Sang Shin, Antonios Tsourdos, Jianjun Luo, "A framework for multi-objective optimisation based on a new self-adaptive particle swarm optimisation algorithm", Information Sciences, vol. 420, pp. 364-385, December 2017.

[17] Deng, Jiamei, Stobart, Richard, Maass, and Bastian, "The Applications of Artificial Neural Networks to Engines," Artificial Neural Networks - Industrial and Control Engineering Applications,pp. 309-332, April 2011.

[18] T. D. Vrionis, X. I. Koutiva and N. A. Vovos, "A Genetic Algorithm-Based Low Voltage Ride-Through Control Strategy for Grid Connected Doubly Fed Induction Wind Generators," in IEEE Transactions on Power Systems, vol. 29, no. 3, pp. 1325-1334, May 2014.

[19] Junhao Zhang, Pinqi Xia, "An improved PSO algorithm for parameter identification of nonlinear dynamic hysteretic models", Journal of Sound and Vibration, vol. 389, pp. 153-167, 17 February 2017. 